Final draft. Published in Topoi, 39: 357-365

https://doi.org/10.1007/s11245-017-9525-1

\title{
Names, descriptions and causal descriptions. Is the magic gone?
}

\section{Genoveva Martí}

ICREA and University of Barcelona

\begin{abstract}
Some of the fundamental lessons of the so-called revolution against descriptivism that occurred in the 70s are negative and it is not immediately apparent what kind of semantic theory should emerge as regards proper names, the alleged paradigms of genuinely referential terms. Some of the claims about names, most notably Ruth Barcan Marcus' characterization of names as tags, appear to be too picturesque to provide the basis for a positive theory and, without a theory, it would seem that the referential link between name and bearer is established by pure magic. Some authors have appealed to the causal-historical picture to construct a positive theory, and have endorsed causal descriptivism, a variety of descriptivism that incorporates causal factors. I argue against causal descriptivism and I assess the demand for a positive semantic theory of names.
\end{abstract}

1.- Names. The search for a semantic theory.

In the early seventies several philosophers of language argued for a radical change of perspective in the conception of reference. Much of the discussion among the early champions of the radical change, most notably Saul Kripke, Keith Donnellan and Ruth Barcan Marcus, focused on proper names, the paradigmatic kind of expression that we use in order to say things about individuals. ${ }^{1}$

The emerging approach is known variously as Direct Reference Theory, Millianism, and Causal o Causal-Historical Theory, and it is also called by some-still now, over forty years down the road - the 'new' theory of reference.

It is quite clear what the proponents of the new theory were arguing against, and for some time the theory was and perhaps still is characterized negatively, as antidescriptivism, by opposition to the paradigm that it intended to debunk. And thus, some of the fundamental lessons of the new approach are couched in negative terms: we

\footnotetext{
${ }^{1}$ Of course, the change of perspective was not meant to apply only to a specific type of expression, for the paradigm that the revolutionaries challenged was a universal theory of how reference, the relation that connects linguistic expressions with the pieces of the world they are about, is possible. So the breakaway affected also indexicals, demonstratives and kind terms.
} 
learned, among other things, that descriptivism is wrong, that proper names do not refer by virtue of being associated with definite descriptions cognitively accessible to the speaker. Some names can be introduced and their reference fixed by description (as was the case with 'Neptune'), but those descriptions do not operate by determining the reference on each occasion of use.

From Kripke's modal argument we learned that names and descriptions have typically different modal profiles, so they cannot be synonymous. And from Kripke's and Donnellan's semantic arguments, based on observation of and reflection on every day practice, we learned that speakers do refer without being in possession of a uniquely identifying description, which shows that the backup of a description is not necessary to refer when using a name. We learned also that even if speakers associate a uniquely identifying description with a name, their uses may not refer to the denoted individual. So descriptions, even when available, do not determine the reference of uses of proper names. ${ }^{2}$

In this regard, names do not operate like indexicals. Whereas every utterance of an indexical has its referent determined by its character (the associated description that constitutes the mechanism or systematic rule that operates on each occasion of use to determine a referent), no description seems to be required to connect a use of a name to its referent.

These anti-descriptivist lessons are mostly negative: the conclusion is about what names are not, and how they do not operate: they are not definite descriptions and they do not operate semantically via definite descriptions. As Ruth Barcan Marcus puts it,

Descriptions are prescriptions for finding an object. The relations between a
name and its referent and between a description and its satisfier are different. (Marcus 1993: 212)

As regards what names are and how they function, Marcus strikes a more positive note when she tells us: 'It [a proper name] simply tags' (1961:310) and 'proper names serve as a long finger of ostension over time and place' (1993: 203). But those

\footnotetext{
${ }^{2}$ See Donnellan 1970 and Kripke 1980. Those arguments, which have come to be known ignorance and error arguments, are illustrated by the 'Feynman'/ Gell-Mann' case (Kripke 1980: 81) and by the 'Columbus' case (Kripke 1980: 85).
} 
remarks seem too picturesque and metaphorical to provide a foundation for an explanation of the mode of operation of a proper name.

The chain of communication, or causal-historical picture, that Kripke and Donnellan advanced would seem to give us a basis for a positive theory of the connection between utterances of proper names and the things they name. And some philosophers, while acknowledging the impact of Kripke's and Donnellan's ignorance and error arguments on classical descriptivism, have defended a form of descriptivism, causal descriptivism, that incorporates elements of the causal-historical approach.

In section 3 of this paper I assess the causal-descriptivist move, endorsing some of the objections posed by its detractors and adding some of my own. In section 4 I discuss the demand for a positive theory of the relation of reference. But first (section 2), I will highlight some of the aspects of the causal-historical approach that will be relevant for the subsequent discussion.

\section{2.- Chains of communication and the causal-historical picture}

'How does my utterance of a name manage to refer to a person, perhaps someone I have never encountered, even someone spatially and temporally distant?' According to the causal-historical picture the answer to that question is that our utterance refers because we are part of a chain of communication that connects our use to previous uses all the way back to the introduction of the name and the referent. It is the objective fact that speakers are part of that chain, not a description in their minds, that makes their utterance designate its referent.

Of course, this is not to deny that the objective fact that a speaker is part of a chain depends partly on events and processes in the speaker's mind; among other things, it depends on her abilities to use names, following conventions of usage present in her community. But the role of the mental in this picture is, quite clearly, very different from the postulation of a cognitively available definite description associated with the name. ${ }^{3}$

But so far, the answer provided by the causal-historical picture is a story about the transmission of the ability to use a name properly, i.e., to refer to its bearer. And that transmission requires that the relation of reference between name and bearer be antecedently established.

\footnotetext{
${ }^{3}$ I thank Michael Devitt for pressing me on this issue.
} 
The appeal to chains of communication is not a solid platform for a theory of reference for proper names. First of all, it is obvious that the existence of chains of communication is not specific to names. The use of any expression in the language is transmitted and propagated from link to link, from generation to generation of speakers as if through a chain. As Joseph Almog (1986: 482) put it, "the historical chain preserves the linguistic meaning of any expression". I use the word 'here' or the word 'tiger' because I have learned and acquired those words from a competent speaker that has passed on to me the capacity to use them and thereby refer to the place where I am located, or to the feline species. This is a fact about how we learn language, how we typically incorporate words to our vocabulary, not a semantic fact. ${ }^{4}$

Second, the chain of communication could have been taken on board even by classical descriptivists, who could have simply proposed that what is passed from link to link of the chain is a reference determining definite description, such as 'the teacher of Alexander'.

But more important: in and of itself, the story of how a name is transmitted through a chain of communication cannot the basis of a positive theory of how names refer, simply because the chain itself does not determine what a particular utterance of a name designates. A Martian anthropologist following the chain of communication back to its sources would observe a collection of acquisitions from prior links, a collection of uses that lead, not to the bearer, but to the bestowal that establishes the connection between name and bearer.

Quite often specific acts of dubbing establish the referential connection and underpin the subsequent uses of names. But it is clear that names are given in many ways, sometimes without there being a specific intentional act of dubbing. In these cases a name is bestowed in use. Michael Devitt notes that "nicknames, in particular, are commonly not bestowed ceremonially, but rather are used, seem apt, and hence

\footnotetext{
4 'Typically' because as Scott Soames has argued some names can be used without being acquired from other speakers. He mentions an example discussed by Jonathan McKeown-Green in which a writer has been told of a region in Ireland in which the residents of different towns see to it that there is always exactly one person bearing the name 'Patrick O'Grady'. Soames and McKeown-Green contend that the writer's use of the name refers, when, for instance, on arriving at a town's pub she proclaims 'I am looking for Patrick O'Grady whom I am willing to pay for an interview for my new book'. (Soames 2005: 301).
} 
catch on" $(1974: 199)^{5}$.

The variety of forms of introduction is not exclusive of names: there are cases in which speakers explicitly agree to use an expression with a certain meaning a metalinguistic 'dubbing' ceremony, but it is unlikely that there was a moment in which a group of speakers endowed with the authority to fix the meanings of words proclaimed: 'We will use 'here' to refer to the place where the speaker is located'. Words acquire their usage in a variety of ways and not always in a sole and distinguishable act that establishes the correct future use.

In any case, the chain of communication leads to a bestowal in use, which is both a bestowal and a designating use, or it leads to a metalinguistic bestowal, an explicit act of dubbing by which a name is mentioned and fixed to a referent. So, the question is: how do first bestowing uses manage to designate? And, how does an explicit act of bestowal manage to connect name and bearer?

A descriptivist will insist: the connection can only be established via a definite description. Let us not forget that descriptivism is not just a view about the semantics of names. Descriptivism is a general view about reference: the view that reference can only be established by the mediation of a definite description. Without such referencefixing mediation, the reference relation between an expression and what it stands for, and in particular the relation between a name and its bearer, is a mystery and it would seem to be established by some kind of magic. But magic just won't do. Frank Jackson's words about the reference of 'water' apply to proper names too:

Although any view about how 'water' gets to pick out what it does will be controversial, it is incredible that there is no story to tell-it is not magic that 'water' picks out what it does pick out—-so we can be confident that there is a reference-fixing story to tell. (Jackson 1998:82 ft. 36)

So, what kind of reference-fixing story can the anti-descriptivist provide for explicit dubbings or bestowing uses, those occasions in which the bond of reference emerges for the first time? Definite descriptions are used sometimes to determine the individual upon which a name is bestowed. But in other occasions, according to the anti-

${ }^{5}$ This is why I have argued that bestowing a name should be seen as a process, for it requires success in establishing a practice (a practice that need not be social). See Martí (2015), especially section 4.3. 
descriptivist, the ability to designate an object with its name -an ability that is transmitted from link to link of the chain of communication - begins with bestowing uses or with dubbing ceremonies in which speakers exercise the ability to make an expression stand for an object

That ability will be probably explained, as Michael Devitt (2015) argues, at the psychological level of language processing and ultimately as Michael Devitt (1974) and Michael Devitt and Kim Sterelny (1999) have suggested, in terms of neurophysiological events, changes and interactions in brain states, and chemical processes in the body.

There is no denying that physical, physiological, chemical and neurophysiological processes are present and accompany the actions and interactions that end in the successful bestowal of a name. Those are fundamentally subpersonal processes. And, again, one does not need to endorse a purely physicalist stance, denying any role to the irreducible mental in the explanation of the capacity to bestow a name. The philosophical point is that the successful bestowing of a name is the result of the exercise of a human ability to make words stand for things. The ability itself can indeed be described, but it can be exercised, according to the anti-descriptivist, without the appeal to a reference-fixing definite description.

Again, this is not an explanation that is exclusive to proper names, nor to language for that matter. It is a general story of the human capacity to make pieces of the world symbols for other pieces of the world; an ability that empowers humans to stipulate that A is a symbol that stands for, or represents, B. I can stipulate that the stick figure I just drew stands for René Descartes, and I can stipulate that drawing a hat on my stick figures stands for the property of having a beard. If I draw a hat on the stick figure that represents Descartes I have thereby represented the state of affairs that Descartes had a beard.

Lots of mental events, and also causal interactions, neurophysiological events, changes in brain states, and chemical processes in the body are at play when all that happens, but deep down the final explanation is simply that A stands for B by stipulation. This does not seem to go far beyond the metaphorical dicta of Ruth Barcan Marcus. The process by which a stick figure, or a name, comes to represent an individual can be described, but the description of the physical and, if one is not a reductive physicalist, mental processes involved is a third person description of objective goings on that falls short from the descriptivist demand. From the descriptivist point of view the causal-historical approach provides a description of the circumstances 
in which reference is established, but it does not explain what establishes the referential bond and so it embraces the mystery and the magic rather than dispelling them. The descriptivist will not accept as satisfactory any explanation that fails to produce a mechanism of selection of a referent that is cognitively accessible to the speaker. Nevertheless, as some authors have urged, the causal historical approach may, after all, hold the key to a satisfactory explanation.

\section{3.- A semantic theory. Causal descriptivism.}

Causal descriptivism seeks to preserve a descriptivist stance by appealing to reference fixing descriptions that incorporate causal elements. The view has its origin in David Lewis who proposed that

the descriptive sense associated with a name might for instance be 'the place I have heard of under the name "Taromeo"" or maybe "the causal source of this token: Taromeo', and for an account of the relation being invoked here, just consult the writings of the causal theorists of reference. [...] Causal descriptivism explains, as the causal theory itself does not, (1) how the way reference is fixed by means of causal chains is part of our semantic common knowledge, and (2) how it depends on our contingent semantic conventions. (Lewis 1997: 353-4, ft. 22)

Causal descriptivists are not unanimous, nor prodigal, when it comes to giving explicit examples of reference fixing causal descriptions. But it appears that the description might be approximately something like 'the individual at the origin of the causal chain of communication connected to my present utterance of N' ${ }^{6}$

The idea exploited by causal descriptivism is that speakers in general know the

\footnotetext{
${ }^{6}$ Approximately, because there is almost universal agreement that the description would have to be considerably more complicated, since it would have to include reference to linguistic conventions and conditions on the successful transmission of words from link to link. For instance, Fred Kroon opens his defense of causal descriptivism by pointing out: "I see no need in this paper to say much about the kind of causal descriptions that play a reference determining role according to causal descriptivism. It is evident that causal descriptions of the form 'the individual referred to by uses of the name $\mathrm{N}$ from which I acquired the use of N' will count, but much more than these should be assigned a role," and he then proceeds to indicate why the description will be considerably more complicated (Kroon 1987: 1, ft. 1. See also Kroon 2004 for further discussion and defense of the view).
} 
linguistic conventions that operate in their community, even if such knowledge is implicit. They rely on other speakers, prior links of the causal chain, to learn words and they typically intend to use the words they acquire with the same meaning, and to refer to the same things as the speakers they acquired their expressions from. That knowledge can be described, and according to the causal descriptivist, that description, implicitly known by speakers, is the reference fixing description that determines the reference of particular utterances of $\mathrm{N}$.

The folk know perfectly well that sentences like 'Feynman worked at CalTech' carry information about Feynman [...] What is more, they know that information transmission is underpinned by causal connections [...] What is more, the folk know that the information about an object carried by sentences containing proper names typically depends on causal chains initiated by the assignment of a name to an object [...] What is more, they know the information carried relies on their language community adopting conventions of usage that mean that sentences containing names preserve information about what is named (Jackson 2010: 5) ${ }^{7}$

Some authors have criticized causal descriptivism pointing out that the description that articulates the conventions and causal factors that are relevant in the successful causal transmission of a name is bound to be extremely complicated, too complicated to be postulated even as an implicit belief held by most regular members of the speakers' community. This is a special concern as regards young children since they seem quite capable of naming things at an age in which it is it is doubtful that their ability is underpinned by the knowledge of a complicated metalinguistic description. But this is ultimately an empirical issue, which I will not dwell on. ${ }^{8}$

Causal descriptivism has also been criticized for confusing two different levels of explanation of semantic phenomena. Most notably, Scott Soames points out:

\footnotetext{
${ }^{7}$ See also Orilia 2010 (especially chapter 5) for a defense of a variety of causal descriptivism.

${ }^{8}$ For other criticisms of causal descriptivism, see Raatikainen 2006 who argues that the view fails to respond to the motivations that speak in favor of the classical descriptivist stance. More recently, Mario Gómez Torrente (forthcoming) has criticised causal descriptivism on the basis of the its inability to represent adequately cases of referential indeterminacy. In his discussion Gómez-Torrente proposes also several alternative, and specific, possible renderings of causal descriptions, something that is hard to find among the proponents of the view.
} 
Egocentric, metalinguistic descriptions associated with names are no more part of their meanings than similar egocentric, metalinguistic descriptions are parts of the meanings of other words in the language. [...] Thus, the general intention that one's use of words conform with the linguistic conventions of one's community translates, in the case of most names, into the intention to use them to refer to whomever or whatever other relevant members of the community use them to refer to. Some such intention is a standard condition on normal language use, not a part of meaning. (Soames 2005: 301).

So, on Soames' view, the causal descriptivist is mistaking a third person description of the way in which names (and other words) are acquired and used to refer to things, an explanation that belongs to metasemantics, for a semantic reference fixing description that is grasped (implicitly or explicitly) by a competent speaker. ${ }^{9}$

Soames' criticisms target the transmission portion of the causal descriptivist story, for they hinge on highlighting the metasemantic role of the competent speaker's reliance on the conventions of the community where she acquires words with an antecedent meaning, words that have an already set use.

But in the case of names, as we have seen, the description that corresponds to the causal chain of transmission cannot be a reference fixer, since it leads at most to dubbings and bestowing uses, and those are the ones that establish the referential link that can be then transmitted.

One of the reasons the alleged reference fixing causal descriptions need to be

\footnotetext{
${ }^{9}$ I use the label 'metasemantic' with some trepidation, for the category is extremely heterogeneous. Metasemantics, or foundational semantics, explores how expressions are assigned to their meanings, but such an inquiry may include answers to historical, sociological and even etymological questions that have little impact on philosophical theories about meaning and, if they are characterized as metasemantic, it is just by virtue of not being semantic. Or it may include answers to questions about the truth conditional contributions of certain kinds of expressions, questions that are clearly at the foundation of semantic theory. It is not entirely clear where the description of how names are introduced and transmitted falls, nor whether that description has different aspects falling under different categories. See Simchen 2017, especially ft. 1, for a succinct characterization of different metasemantic projects.
} 
more complicated is precisely the need to account for name introduction. ${ }^{10}$ When someone bestows a name on an object the referential link is not established by the existence of a chain; and users that dub simply by using a name are not relying on a chain either -there simply is no chain. The confusion between semantics and metasemantics pointed out by Soames is also patent at the bestowal stage.

And it is worth focusing very especially on the process of name bestowal, for it will allow us to uncover other reasons to raise further concerns against causal descriptivism.

The causal descriptivist needs to postulate a reference fixing description that establishes a fresh referential link between a name and its referent. One alternative is to postulate a definite description that articulates the details of the causal interactions, neurophysiological and mental events that operate in the introduction occasions, a description that captures Michael Devitt's presentation of the way in which the ability to name is acquired. But the majority of those events and processes are subpersonal. Postulating implicit knowledge of such a description would not just be implausible because of the complicated nature of the description, nor would it be just a conflation of semantics and metasemantics; it would be a confusion of the implicit and the subpersonal. It would be decidedly implausible to attribute knowledge, even implicit knowledge, of those subpersonal processes to an agent, and make that knowledge a requirement to bestow names.

Thus, it is more likely that the description the causal descriptivist postulates is more generic and that it encodes the implicit knowledge that members of a community have of the conventions that are in effect in their community; in particular, the conventions for the bestowal of names. In our community speakers know that parents decide the names of their children, that official christenings are dubbings, that someone who uses a name for the first time, while very obviously looking at or pointing at an individual is trying to establish a referential bond and inviting us to join her in the practice of using that name when we want to say something about that individual. This is not a point of contention between the causal descriptivist and the non-descriptivist.

\footnotetext{
${ }^{10}$ And indeed this is one of the reasons Kroon insists that 'the individual referred to by uses of the name N from which I acquired N' will not be enough: "I may be the first to introduce the term N" (1987:1 ft. 1)
} 
Pace Jackson, who views the non-descriptivist as postulating lack of knowledge on the part of the folk, everyone should agree here. ${ }^{11}$

The causal descriptivist and the non-descriptivist agree that there are conventions, in particular, conventions for naming and for using names, and that speakers have knowledge of the conventions that govern their social and linguistic community. But one thing is to postulate that members of a community have a certain know-how as regards the conventions upon which the success of social life depends on( as Jane Austen would put it), and a different thing is to postulate knowledge of the description of uses and customs that an anthropologist observing the society in question would write about (or that Ms. Manners would include in her manual of etiquette and politeness), even if such knowledge is pushed under the umbrella of the implicit. ${ }^{12}$

Perhaps the descriptivist stance is motivated by the conviction that the exercise of an ability or the conforming to a convention requires being in possession of a description that articulates that ability or that convention. It would seem then that for the causal descriptivist a certain form of (tacit) knowing-that is required in the exercise of abilities and competencies, the latter being primary examples of knowing-how. So, perhaps one of the motivations for causal descriptivism is the assumption that knowinghow is a form of or is always accompanied by the corresponding knowing-that, a view that requires justification. ${ }^{13}$

But even if we concede for the sake of the argument that competent speakers have implicit propositional knowledge of the conventions of bestowal of names, causal descriptivism continues to be problematic. In fact, making such a concession brings to the surface yet another flaw in the causal descriptivist stance on naming.

For, if causal descriptivism is to be a form of descriptivism, it has to postulate that the referential link between name and bearer is established by a definite description,

11 “. ... the causal theory of reference is the view . . . that the only thing wrong with causal descriptivism is that it holds that the folk know the causal descriptions that determine the reference of the name " (Jackson 2010:115). Of course the nondescriptivist does not think that descriptions fix the reference of a name, but that is independent of the issue of knowledge.

12 The concern about complication arises also here. The processes and conditions of successful introduction of a name are rather complex and hence the description of those conditions would be extremely complicated.

${ }^{13}$ Such a view is controversial. It has been explored and defended by Stanley and Williamson (2001). Their arguments are challenged by Ian Rumfitt (2003) and Michael Devitt (2011). 
to wit, the definite description that articulates the conventions on naming; the referential link cannot be established just by the performance of actions, accompanied by the presence of appropriate beliefs and intentions, that conform to the conventions: for a descriptivist, the job can only be done by a definite description.

But this is puzzling: in order for the definite description that articulates the conventions for naming to fix the reference, the conventions must be in place and they must be operative, namely, acting according to the conventions (plus having the requisite beliefs and intentions) must be what fixes the reference, what constitutes successful name bestowal. And if the conventions are operative, if they do fix the reference, the definite description the causal descriptivist appeals to is no more than an idle wheel: it does not fix the reference. The anti-descriptivist could even grant that the description the causal descriptivist appeals to articulates the implicit knowledge that speakers have of language and of the linguistic conventions operative in their community; but that does not alter the fact that such a description is simply idle in the reference fixing task. This is a form of self-undermining descriptivism for, deep down, it is no descriptivism at all.

The appeal to a causal description appears to be just a remnant of the insistence that reference has to be mediated by a definite description, some definite description or other.

To sum up, even if the causal descriptivist and the anti-descriptivist agree that speakers have some form of knowledge of the norms and conventions that govern language, and even if they both agree that typically speakers acquire the use of expressions via a chain of transmission, the anti-descriptivist has several serious concerns, rightly in my view: first, that the causal descriptivist is confusing two levels of explanation, by taking a metasemantic description to be a semantic mechanism of determination of reference. Second, that the causal descriptivist is taking for granted that the sort of knowledge of conventions that underpins linguistic behavior has to be a form of knowing-that. And finally, that even granting that the speakers' knowledge of linguistic conventions is propositional, what is really performing the task of establishing the referential link between name and bearer are the processes, actions, beliefs and intentions that conform to convention, not the definite description that articulates them.

4.- Back to the magic? 
What are we left with? If the description that articulates the conditions that govern the reference-preserving transmission of names belongs to metasemantics, and so does the description of the conventions that govern name bestowal, if those are not semantic reference fixing descriptions, what can we say about the semantics of names? Of course we can explain (by appeal to psychological, neurophysiological, historical and socialconventional facts) how the name was bestowed and how the referential use has been preserved, but if that is metasemantics, where is our semantic theory for names? Saying that the semantic function of a name is to stand for its referent appears to be the only semantic claim we are left with. But this is no more philosophically substantial than Ruth Barcan Marcus' picturesque characterization of names as tags.

However, even though Marcus' remarks may seem too thin, philosophically speaking, they reveal, in my view, what the non-descriptivist conception of how proper names refer should be. Ruth Barcan Marcus did not write a specific essay or set of essays developing explicitly her views about reference, but I think that we find scattered in her writings sufficient evidence to form an adequate picture of her views.

Nevertheless, perhaps because of the lack of an explicit standard declaration of what the view amounts to, I think that there is a general failure to appreciate what the crucial tenets of the view that Marcus espoused are, and there are some confusions worth dispelling. For instance on occasion of the award of the Lauener Prize in 2008, Timothy Williamson interprets Marcus' contribution as follows:

One of the ideas $[\ldots .$.$] that resonates most with current philosophy of language is$ that of proper names as mere tags, without descriptive content. This [...] is the idea, later developed by David Kaplan and others, that proper names are directly referential, in the sense that they contribute only their bearer to the propositions expressed by sentences in which they occur. (Williamson 2015: 14)

But Ruth Barcan Marcus' ideas about reference, her understanding of what a referential device is and how it operates are different from the ideas that gave rise to the notion of direct reference, understood in terms of the contribution of referents to propositions.

The idea that proper names are introduced by fiat, that they are conventional marks, tags, is really important for Marcus and it appears time and again in her work. And it is important for two reasons. First, because it distinguishes names from definite 
descriptions, the latter being the paradigmatic kind of expression that designates by characterizing an object:

To count as a proper name, the expression must refer without being tied to any particular characterization of the object. (Marcus 1975: 36)

The distinction between tagging and describing is underwritten by a more fundamental, distinction: that between object and property:

Proper names have a logically irreducible use. They permit us to entertain a separation in language of the object under discussion from its properties. (Marcus 1975: 36) $)^{14}$

The second reason for the importance of the idea of tagging is that it stresses the fact that the relation between a name and its bearer occurs by convention, without the mediation of associated internally graspable mechanisms of reference.

This is why Williamson's characterization of the importance of Marcus' contribution is not accurate. Focusing on the truth conditional contribution of expressions to propositions fails to distinguish names from indexicals and demonstratives. Uses of indexicals also contribute their referents to the truth conditional content expressed by the uses of sentences in which they occur. But indexicals are a paradigmatic example of expressions associated with a reference determining mechanism. When we use an indexical or a demonstrative, we are very obviously not using a tag. We are using and expression that is governed by a rule of use.

Direct Reference theorists, in general, agree with the claim that a name refers without it being associated with an internal mechanism that singles out the referent. It seems an almost obvious inference that in such cases the referent is the semantic contribution that enters the determination of truth conditions, the constituent of the proposition (the idea developed by Kaplan). But it is a mistake is to presume that the truth-conditional contribution is all there is as a special mark of the semantic function of names, without noticing that not all uses of expressions that contribute an object to truth conditions (and to propositions) are free of associated mechanisms. Indexicals and

${ }^{14}$ See Martí 2017 for a discussion of how this distinction affects recently proposed views that treat proper names as predicates. 
demonstratives are the prime example; they designate via a character rule, a rule of meaning that works as a mechanism of selection of the designatum in a context of use.

Ruth Barcan Marcus pushes us to focus away from the truth conditional contribution, and to pay attention to the mode of connection between expression and referent and, on that count, names and indexicals are entirely different, the latter being much closer to definite descriptions, not in their truth conditional contribution, but in their mode of connection to the things they apply to. ${ }^{15}$

As an aside, it is worth noting that it is often pointed out, but not fully appreciated in my view, that descriptivism cannot be an overall picture of the way expressions connect to referents. The words found in descriptions are themselves conventional tags for properties and relations. As Devitt and Sterelny have stressed:

... there must be some terms whose referential properties are not dependent on others. Otherwise, language as a whole is cut loose from the world. Description theories, which explain one part of language in terms of another, can give no clue as to how, ultimately, language is referentially linked to reality. These theories pass the referential buck. But the buck must stop somewhere. (1999: 51-52)

Curiously, the importance of this issue did not escape Bertrand Russell, the paramount proponent of classical descriptivism. Six years after the publication of 'On Denoting' and long after having officially declared that proper names are abbreviations of definite descriptions, Russell tells us:

In the first place it should be observed that the author of Waverley is not a mere name, like Scott. Scott is merely a noise or shape conventionally used to designate a certain person . . . But the author of Waverley is not merely conventionally a name for Scott; the element of mere convention belongs here to the separate words, the and author and of and Waverley. (Russell 1976: 163)

Simple, unstructured words are conventional marks. Some, like 'author', 'red' or 'tall' stand for properties or relations. Even the foremost proponent of the view that names

\footnotetext{
${ }^{15}$ Another misconception as regards Marcus' contributions consists in interpreting her stance as a precursor of the notion of rigidity. I have argued against this misconception in Martí 2012.
} 
are abbreviations of definite descriptions acknowledged that there has to be in language some basic form of connection between words and what they stand for that is not mediated, a bond that holds just by virtue of convention. It is difficult to understand why accepting the same for names should be resisted. And in the fragment just quoted Russell himself, forgetting his own official views about names, seems quite ready to submit.

But, the descriptivist nevertheless insists: without internally grasped reference fixing mechanisms, if all we can say is that the semantic function of names is to stand for their referents, we really do not have a semantic theory of how names refer, no matter how much we eventually succeed in explaining how speakers manage to use names to refer. Is the connection between name and bearer explained by magic, as Jackson complains?

Well, no, it is not magic, although the explanations the non-descriptivist seeks to provide are not the kind of semantic analysis of the relation of naming that the descriptivist demands. But there is a story to tell about how the institution of naming emerges, how the human practice of using names came about. There were surely evolutionary mishaps and lucky turns that explain how intelligent beings acquired the ability to use representations, and among those, words. And there is also a story to be told about the bestowal of each particular name: physical, neurophysiological and mental happenings that make possible the introduction and transmission of names; and an account of the complex conventions that govern bestowing and use.

Telling part of that story requires philosophical reflection and it undoubtedly raises philosophical questions. But another part of the account of all the happenings and processes that determine successful naming and successful subsequent use cannot be provided just by philosophers from their proverbial armchair.

The kind of explanation endorsed in Devitt (1974) and Devitt and Sterelny (1999), recapitulated and further discussed in detail in Devitt (2015), calls for research that involves psycholinguistics as much as philosophical reflection. Much of the research is still forthcoming, so the explanations are incomplete, and hence Devitt (2015) is peppered with remarks such as

... we must look to psycholinguistics to throw more light on [those processes]. Still, given the current state of our knowledge of language processing, we should not expect too much now. (Devitt 2015:14) 
I agree that psycholinguistics, neuroscience and other empirical sciences will contribute to explain the processes that form the basis of the ability to introduce and use names. Yet, I do not think that we should expect or assume that we will obtain a unified theoretical account that can be constitutively incorporated into a semantics of proper names. ${ }^{16}$ For physical and mental processes may underpin the exercise of those abilities, but they may well vary from person to person. Take for instance the ability to perform additions. Different people may exercise that ability in different ways, as a product of different mental and neurophysiological processes. Still, they all exercise the same ability. Those mental and neurophysiological processes certainly underpin the ability to add, but we should not expect that exploring them will uncover a unique mechanism and a unique explanation of the ability to add. And, yet, it would be preposterous to say that we perform additions just by magic. ${ }^{17}$

Nevertheless, the discussion around the desideratum for a unified explanation on the basis envisaged by the likes of Michael Devitt is moot for the descriptivist. For no matter how complete and detailed such explanation turns out to be, no matter how informed by science, it will be unacceptable, if it does not come in the form of a cognitively accessible description that mediates reference. But if such an explanation is magic, let us embrace magic. ${ }^{18}$

\section{References}

Almog, J. 1984: 'Semantical Anthropology'. Midwest Studies in Philosophy, vol. ix: 479-489.

Devitt, M. 1974: 'Singular Terms'. The Journal of Philosophy, 71(7): 183-205.

Devitt, M. 1981: Designation. New York: Columbia University Press.

\footnotetext{
${ }^{16}$ And I am not completely sure how much Devitt believes a unified account to be likely or expected.

${ }^{17}$ I thank Catherine Elgin and Carl Hoefer for a helpful discussion on this point.

${ }^{18}$ Parts of this paper were delivered at the APA Eastern Division Meeting session on Ruth Barcan Marcus, in December 2012 and at the Warsaw Context, Cognition and Communication Conference in 2016. I thank the audiences for their comments. I am also extremely grateful to Michael Devitt, Carl Hoefer and two anonymous referees for their extensive and helpful comments on a previous version. The research for this paper has been supported by the Spanish MINECO's grant FFI2015-70707-P and the Diaphora Project (H2020-MSCA-ITN-2015-675415).
} 
Devitt, M. 2011: 'Methodology and the Nature of Knowing How'. The Journal of Philosophy, 108(4): 205-218.

Devitt, M. 2015: 'Should Proper Names Still Seem So Problematic?'. A. Bianchi (ed.) On Reference. Oxford University Press: 108-143.

Devitt, M. and Sterelny, K. 1999: Language and Reality. An Introduction to the Philosophy of Language. Second Edition. Oxford: Blackwell Publishers.

Donnellan, K. 1970: 'Proper Names and Identifying Descriptions'. Synthese, 21(3-4): 335-358.

Gómez-Torrente, M. (forthcoming): Roads to Reference. An Essay on Reference Fixing in Natural Language.

Jackson, F. 1998: From Metaphysics to Ethics. Oxford University Press.

Jackson, F. 2010: Language, Names and Information. Wiley-Blackwell.

Jeshion, R. 2009: ‘The Significance of Names.” Mind \& Language 24: 372-405.

Kripke, S. 1980: Naming and Necessity. Harvard University Press.

Kroon, F.W. 1987: 'Causal Descriptivism'. Australasian Journal of Philosophy, 65(1): $1-17$.

Kroon, F.W. 2004: 'Millian Descriptivism'. Australasian Journal of Philosophy, 82(4): 553-576.

Lewis, D. 1984: 'Putnam's Paradox'. Australasian Journal of Philosophy, 62(3): 221236

Lewis, D. 1997: 'Naming the Colours'. Australasian Journal of Philosophy 75(3): 32542 .

Marcus, R.B. 1961: 'Modalities and Intensional Languages'. Synthese, 13(4): 303-322.

Marcus, R.B. 1975: 'Does the Principle of Substitutivity Rest on a Mistake?'. A.R. Anderson et al. (eds.): The Logical Enterprise. Yale University Press: 31-38.

Marcus, R. B. 1993: 'Possibilia and Possible Worlds'. Reprinted in her Modalities. Oxford University Press (originally published in Grazer Philosophische Studien 25/26 (1985/86): 107-33).

Martí, G. 2012: 'On Modality and Reference. Ruth Barcan Marcus (1921-2012)'. Teorema, 31(2): 203-212.

Martí, G. 2015: 'Reference without cognition'. A. Bianchi (ed.) On Reference. Oxford University Press: 77-92 
Martí, G. 2017: 'Names, predicates and the object—property distinction'. M. De Ponte and K. Korta: Reference and Representation in Thought and Language. Oxford University Press: 14-19.

Orilia, F. 2010: Singular Reference. A Descriptivist Perspective. Springer.

Raatikainen, P. 2006: ‘Against causal descriptivism' Mind \& Society, 5(1): 78-84.

Rumfitt, I. 2003: 'Savoir Faire'. The Journal of Philosophy, 100(3): 158-166.

Russell, B. 1976: 'Knowledge by Acquaintance and Knowledge by Description'. Mysticism and Logic. Barnes \& Noble: 152-167.

Simchen, O. 2017: 'Metasemantics and Singular Reference'. Noûs, 51(1): 175-195.

Soames, S. 2005: Reference and Description. The Case against Two-Dimensionalism. Princeton University Press.

Stanley, J. and Williamson, T. 2001: 'Knowing How'. The Journal of Philosophy, 98(8): 411-444.

Williamson, T. 2015: 'Laudatio. Ruth Barcan Marcus'. M. Frauchiger (ed.), Modalities, Identity, Belief, and Moral Dilemmas: Themes From Barcan Marcus. De Gruyter: 1116. 